\title{
Knowledge on malignant hyperthermia: as rare as the disease? A nation wide survey
}

\author{
Timothy Wolvetang ${ }^{1 *}$, Jan Hofland ${ }^{2}$, Hanneke Takkenberg ${ }^{1}$ \\ From 33rd Annual Meeting of the European Malignant Hyperthermia Group (EMHG) \\ Würzburg, Germany. 15-17 May 2014
}

\section{Background}

Knowledge on malignant hyperthermia $(\mathrm{MH})$ has expanded vastly during the past decades, but not everyone is up to date on all this newfound knowledge. To assess the current level of knowledge on $\mathrm{MH}$, a survey was performed among Dutch anaesthesia personnel. Research questions were: What is the current general knowledge of anaesthesia personnel about $\mathrm{MH}$; furthermore, do anaesthesiologists (in training) know more than (trainee) nurse anaesthetists; and, does experience with a $\mathrm{MH}$ crisis and/or triggerfree anaesthesia result in a better overall knowledge score?

\section{Materials and methods}

The survey consisted of an online questionnaire, responders were recruited via Dutch social media groups for anaesthesia personnel. The survey entailed 12 questions, 3 of which assessed the responders profession, hospital, and whether the participant had previously encountered $\mathrm{MH}$ in their practice (i.e. $\mathrm{MH}$ crisis and/or triggerfree anaesthesia). The other 9 questions assessed the existing knowledge on $\mathrm{MH}$. The questions covered various important aspects of $\mathrm{MH}$ : knowledge on the incidence, triggers, symptoms, prevention, (importance of early) recognition, and treatment. The maximum possible score was 12 points. Crosstabs and one way anova analysis was performed with SPSS Statistical software package version 21 for statistical analysis, $\mathrm{P}<0,05$ was taken to represent significance. Correctness of the answers was assessed in relation to the available literature and EMHG guidelines on the subject.

Table 1 Percent correct answers per question and total score, $* \mathbf{P}<0.05$ between groups

\begin{tabular}{|c|c|c|c|c|c|}
\hline Question subject & $\begin{array}{c}\text { Total } \\
\text { correct }\end{array}$ & $\begin{array}{l}\text { Anaesthesiolo- } \\
\text { gists }\end{array}$ & Residents & $\begin{array}{c}\text { Nurse } \\
\text { Anaesthetist }\end{array}$ & $\begin{array}{l}\text { Trainee Nurse } \\
\text { Anaesthetist }\end{array}$ \\
\hline Prevalence & $4.8 \%$ & $9.1 \%$ & $0.0 \%$ & $7.1 \%$ & $0.0 \%$ \\
\hline $\begin{array}{l}\text { Prevention (how long should ventilator be flushed with } \\
\text { O2) }\end{array}$ & $22.8 \%$ & $27.3 \%$ & $25.0 \%$ & $23.8 \%$ & $11.8 \%$ \\
\hline Importance of recognition of early symptoms & $35.6 \%$ & $63.6 \% *$ & $30.0 \% *$ & $23.8 \% *$ & $35.3 \%^{*}$ \\
\hline Recognition of tachycardia as early symptom & $60.4 \%$ & $68.2 \%$ & $65.0 \%$ & $50.0 \%$ & $70.6 \%$ \\
\hline Basic triggering medication & $74.3 \%$ & $77.3 \%$ & $85.0 \%$ & $66.7 \%$ & $76.5 \%$ \\
\hline Advanced triggering medication & $1,0 \%$ & $0.0 \%$ & $0.0 \%$ & $2.4 \%$ & $0.0 \%$ \\
\hline Stress as trigger & $64.4 \%$ & $77.3 \%$ & $70.0 \%$ & $64.3 \%$ & $41.2 \%$ \\
\hline Cardiopulmonary bypass as trigger & $32.7 \%$ & $50.0 \% *$ & $50.0 \% *$ & $19.0 \% *$ & $23.5 \% *$ \\
\hline Basic knowledge on later symptoms & $30.7 \%$ & $40.9 \% *$ & $50.0 \% *$ & $16.7 \%^{*}$ & $29.4 \%^{*}$ \\
\hline Advanced knowledge of later symptoms & $10.9 \%$ & $18.2 \%$ & $15 \%$ & $2.4 \%$ & $17.6 \%$ \\
\hline Dosage of Dantrolene IV & $38.6 \%$ & $45.5 \%$ & $55.0 \%$ & $23.8 \%$ & $47.1 \%$ \\
\hline Triggering time of $\mathrm{MH}$ & $35.6 \%$ & $59.1 \% *$ & $35.0 \% *$ & $23.8 \% *$ & $35.3 \% *$ \\
\hline Total score (average, max 12) & 3.51 & $4.68^{*}$ & $4.15^{*}$ & $2.74^{*}$ & $3.18^{*}$ \\
\hline
\end{tabular}

'Department of Cardio-thoracic surgery, Erasmus MC, Rotterdam, 3000,

Netherlands

Full list of author information is available at the end of the article

(c) 2014 Wolvetang et al; licensee BioMed Central Ltd. This is an Open Access article distributed under the terms of the Creative 


\section{Results}

A total of $104(n=104)$ responders entered the survey, of which 22 were anaesthesiologists; 20 residents; 42 nurse anaesthetists; 17 trainee nurse anaesthetists; 3 did not specify their profession. Among responders 52 subjects had no previous experience with $\mathrm{MH}$ in practice, as opposed to 51 who did have experience $(1$ subject did not specify), the latter group had a significantly higher knowledge score. Results of the knowledge questions and total knowledge scores are shown in table 1 .

\section{Conclusions}

Knowledge on $\mathrm{MH}$ is not quite as rare as the disease but certainly needs improvement as evidenced by this survey. Anaesthesiologists and residents have significantly better knowledge than (trainee) nurse anaesthetists. Yet the highest average knowledge score of 4.68 out of a maximum of 12 points is disappointing reflecting insufficient basic knowledge on $\mathrm{MH}$. These observations call for improved knowledge dissemination of this rare but very dangerous complication of anaesthesia. Means by which this might be achieved is simulation education as anaesthesia personnel with experience have a significantly better knowledge score.

\section{Authors' details}

'Department of Cardio-thoracic surgery, Erasmus MC, Rotterdam, 3000, Netherlands. ${ }^{2}$ Department of cardio-thoracic Anaesthesiology, Erasmus MC, Rotterdam, 3000, Netherlands.

Published: 18 August 2014 